\title{
Effect of Ionospheric Perturbation on GPS Observation over Low Latitude Region, Bhopal
}

\author{
S. Chatterjee ${ }^{1}$ and P. K. Purohit ${ }^{2 *}$ \\ ${ }^{1}$ Technocrats Institute of Technology, Bhopal, India \\ ${ }^{2}$ National Institute of Technical Teachers’ Training and Research, Shamla Hills, Bhopal 462002, \\ India
}

Received 20 March 2012, accepted in final revised form 22 August 2012

\begin{abstract}
Increased knowledge on the ionospheric structure is of important interest for precise positioning, since the ionosphere has an impact on global positioning system (GPS) L-band radio waves by its free electrons. Especially during perturbed geomagnetic conditions when the ionosphere differs from its undisturbed state, quasi real time data assimilation would be useful. On the other hand, these perturbations of the GPS signals are taken as scientific information to investigate ionospheric scenarios. In this paper we describe the occurrence of GPS phase fluctuations during January to December 2005 events on the basis of Bhopal GPS observations. This study concerns the analysis of strong phase fluctuations which were associated with geomagnetic storms. The intensive total electron content (TEC) fluctuations observed along GPS satellite passes, demonstrate a strong horizontal gradient of TEC and difficulties with the carrier phase ambiguity in relative GPS positioning. In turn, the phase fluctuations can cause cycle slips.

Keywords: Global positioning system; Phase fluctuations; Geomagnetic storms; TEC; Cycle slips.

(c) 2012 JSR Publications. ISSN: 2070-0237 (Print); 2070-0245 (Online). All rights reserved. doi: http://dx.doi.org/10.3329/jsr.v4i3.10146 J. Sci. Res. 4 (3), 577-587 (2012)
\end{abstract}

\section{Introduction}

During the last decade GPS has become an interesting tool for ionospheric investigations. One-dimensional profiling [1,2] allows retrieving information on the vertical structure of the ionosphere. For this purpose, signals from GPS satellites orbiting the Earth at about 20,200 km are received during so-called occultation at LEO (low earth orbit) satellites at orbit altitudes lower than $800 \mathrm{~km}$. A great advantage of this occultation technique lies in the global distribution of the retrieved profiles. Regarding the present amount of satellites profile coverage is still sparse although promising. Two-dimensional mapping of GPS data to vertical TEC [3] pose another application. Hereby, the vertical integrated

\footnotetext{
*Corresponding author: purohit_pk2004@yahoo.com; sbhattacharya_82@yahoo.co.in
} 
measurements of the electron content are mapped to the Earth's surface. This method is based on ground received data and allows a regional continuous monitoring of the ionosphere. This method is expected to be a tool for retrieving vertical and horizontal information. The inversion of the integrated (total electron content) TEC values to threedimensional electron density patterns is a third possibility of monitoring the ionosphere with GPS data. The ionospheric behavior during quiet conditions is well known and efficiently modeled by the International Reference Ionosphere (IRI) [4]. However, knowledge of the ionospheric response during geomagnetic storms and related process remains incomplete. To predict and model the ionospheric response during storms is therefore a high priority. There have been several attempts to simulate the storm-time response of the thermosphere and ionosphere using theoretical models [5] and Parameterized Ionospheric Models (PIM) [6]. There are, however, a number of physical processes operating during a storm that can result in changes in the ionosphere. During a storm, changes in the neutral wind occurred that directly impact the ionosphere, as well as through which neutral composition changes can occur. Electric field can strip away plasma to high mid-latitude and can penetrate to low latitudes. The ionospheric responses to all of the physical processes are very difficult to capture and understand even with a complex physical model, and are even more difficult to capture in a simple empirical model. The details of the ionospheric response to a particular storm therefore are unique due to the many physical processes involved and due to the complexity of the driving processes from the magnetosphere. Thus, TEC measurement is a powerful new method for studying and monitoring the processes of development of an ionospheric storm. This paper presents an analysis of the occurrence of strong phase fluctuations of GPS signals observed at Bhopal, low latitude station. The ionosphere irregularities are responsible for phase fluctuations of GPS signals. Phase fluctuations are caused by large scale irregularities. During storm intensity phase fluctuations essentially increased. Because of the depressive nature of the ionosphere the dual frequency GPS phase measurements provide useful information about variations of the ionospheric total electron content. In refs. [7-9] it has been observed that during low solar activity period also TEC shows much impact on ionosphere as well as space weather events greater at low latitude than at mid latitude. Rapid fading takes place in the two layers $\mathrm{E}$ and $\mathrm{F}$ at different epochs of solar cycle also has also been observed [8]. The close relationship between the geomagnetic indices and the ionospheric perturbations in the magnetic field can cause large gradients in the TEC at earth's altitudes have been reported in refs. [10]. So the knowledge of this gradient is important for different GPS users. The GPS can be used for the study of magnetic storms; otherwise it is a comprehension tool for the earth solar environment. Several studies used GPS observations to monitor TEC fluctuation caused irregularities [11-12].

\section{Data and Methodology}

For analysis of the temporal variations of different carrier phase the GPS signals passes along individual satellite were used. The indices Rate of TEC (ROT) on 1 min interval 
and RMS value of TEC rate expressed in TECU/min have been used [13] as a measure of the activity of phase fluctuations. In this paper we describe the occurrence of GPS phase fluctuations during January 2005 to December 2005 events on the basis of Bhopal GPS observations. This study concerns the analysis of strong phase fluctuations which were associated with geomagnetic storms. In our study, TEC data at a rate of change of $1 \mathrm{~min}$, ROT, were used to estimate phase fluctuations. When using ROT we avoid the problem of phase ambiguities. Short-term changes in ionospheric TEC were computed over a oneminute time interval. The rate of TEC (ROT) is defined as in [14]

$$
\operatorname{ROT}^{i}\left(t_{k}\right)=\frac{\operatorname{TEC}^{i}\left(t_{k}\right)-T E C^{i}\left(t_{k-1}\right)}{\left(t_{k}-t_{k-1}\right)}
$$

where $i$ denotes the observation to the $i^{\text {th }}$ satellite and $k$ is the time epoch. When computing ROT we only use the phase measurements.

To quantify the degree of the disturbances, we calculate the RMS value of ROT values within 5 min period for all satellites observed, based on the following equation,

$$
R M S=\sqrt{\sum \frac{(R O T-u)^{2}}{n}}
$$

where $n$ is total number of observations in 5 min, and $u$ is the average of ROT.

Since each storm has its separate effects on the ionosphere. The events are divided into three groups according to the strength of Dst; Strong (Dst > -90nT), Moderate (-30nT < Dst $<-90 \mathrm{nT}$ ) and Small (Dst<-30 nT). The parameter which monitors the different phases of the geomagnetic storm is the equatorial Dst $(\mathrm{H})$ index. The value of equatorial Dst $(\mathrm{H})$ index, AE, the auroral electrojet index and vertical component of interplanetary magnetic field values are taken from the Advance Composition Explorer (ACE) satellite Data Service of World Data Centre. In the present work we have considered 25 storms as shown in Table 1 out of which 5 are weak storms, 13 moderate and 7 strong storms during the period of January 2005- December 2005.

Table1. List of Storms during the period of January 2005 - December 2005.

\begin{tabular}{clccl}
\hline Sl. & \multicolumn{1}{c}{ Date } & Dst minimum & Time & Category \\
\hline 1 & 7 January 2005 & $-59 \mathrm{nT}$ & 0922 & Moderate \\
2 & 9 January 2005 & $-39 \mathrm{nT}$ & 1041 & Moderate \\
3 & 17 January 2005 & $-74 \mathrm{nT}$ & 0748 & Moderate \\
4 & 21 January 2005 & $-99 \mathrm{nT}$ & 1711 & Moderate \\
5 & 4 April 2005 & $-55 \mathrm{nT}$ & 1307 & Moderate \\
6 & 6 May 2005 & $-3 \mathrm{nT}$ & 1307 & Weak \\
7 & 7 May 2005 & $-29 \mathrm{nT}$ & 1916 & Weak \\
\hline
\end{tabular}


Contd. Table 1

\begin{tabular}{rlrll}
\hline 8 & 15 May 2005 & $-263 \mathrm{nT}$ & 0238 & Strong \\
9 & 20 May 2005 & $-103 \mathrm{nT}$ & 0401 & Strong \\
10 & 28 May 2005 & $-43 \mathrm{nT}$ & 0436 & Moderate \\
11 & 29 May 2005 & $-46 \mathrm{nT}$ & 0952 & Moderate \\
12 & 12 June 2005 & $-105 \mathrm{nT}$ & 0745 & Strong \\
13 & 14 June 2005 & $-35 \mathrm{nT}$ & 1835 & Moderate \\
14 & 16 June 2005 & $-41 \mathrm{nT}$ & 0847 & Moderate \\
15 & 10 July 2005 & $-94 \mathrm{nT}$ & 0337 & Strong \\
16 & 13 July 2005 & $-54 \mathrm{nT}$ & 0512 & Moderate \\
17 & 17 July 2005 & $-46 \mathrm{nT}$ & 0134 & Moderate \\
18 & 27 July 2005 & $-14 \mathrm{nT}$ & 1939 & Weak \\
19 & 24 August 2005 & $-216 \mathrm{nT}$ & 1613 & Strong \\
20 & 30 August 2005 & $-19 \mathrm{nT}$ & 1908 & Weak \\
21 & 2 September 2005 & $-50 \mathrm{nT}$ & 1419 & Moderate \\
22 & 9 September 2005 & $-38 \mathrm{nT}$ & 1401 & Moderate \\
23 & 11 September 2005 & $-147 \mathrm{nT}$ & 0114 & Strong \\
24 & 15 September 2005 & $-86 \mathrm{nT}$ & 0835,0904 & Moderate \\
25 & 27 October 2005 & $-23 \mathrm{nT}$ & 1156 & Weak \\
\hline & & & & \\
\hline
\end{tabular}

\section{Result and Discussion}

The observations of total electron content (TEC) by GPS can contribute to understanding of the characteristics of ionospheric perturbations. The storm time relationship between the perturbation component of TEC and geomagnetic fields has been experimentally examined by several investigators $[12,15,16]$.

\subsection{Weak storms}

During the period of January 2005 to December 2005 there are 05 weak storms occur. Here we have considered the weak storms that occur on $27^{\text {th }}$ July 2005 and $27^{\text {th }}$ October 2005. Weak storms means that they have their minimum Dst <-30 nT. Figs. 1 present an example of weak storm which occurred over low-latitude region in India, during the magnetic storm of 27 July 2005. As shown in the top three panel of Fig.1 AE, Dst and the variation of interplanetary magnetic field (IMF Bz), are depicted, respectively, during 2628 July 2005. On 27 July, the ground magnetic field measurement show that a sudden commencement occurs at 1939 UT and around 0600 UT (next day i.e. 28 July) the Dst reaches its value of $-50 \mathrm{nT}$. AE also show its maximum values of $1095 \mathrm{nT}$ and $1004 \mathrm{nT}$ on the same day i.e. on 28 July. But on 27 July, the IMF Bz starts fluctuating over the entire 
day and showed a strong negative component of $12.18 \mathrm{nT}$ at $2000 \mathrm{UT}$. Now the top panel of Figs. 2 the RMS of TEC rate (RMS of ROT ) and the second panel shows the equivalent vertical TEC fluctuations for the storm we have considered. Large and rapid fluctuations in TEC were observed during the storm time. It shows that during geomagnetically disturbed days, RMS of TEC rate appears quite irregular and reaches as high as 0.49 on 27 July with VTEC of 36.25 TECU.

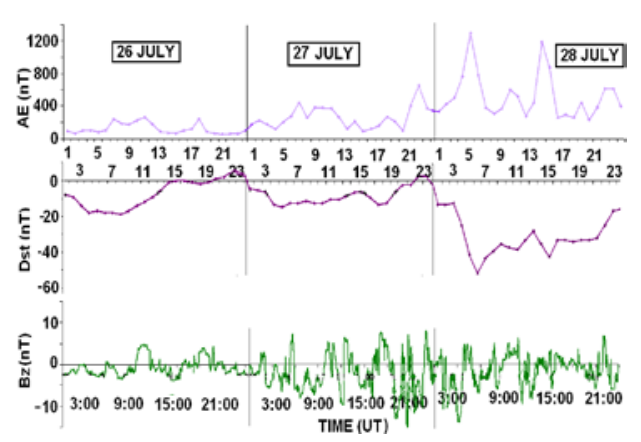

Fig. 1. Storm event of 27 July 2005 with $\mathrm{AE}(\mathrm{nT})$, Dst (nT) and Bz (nT).

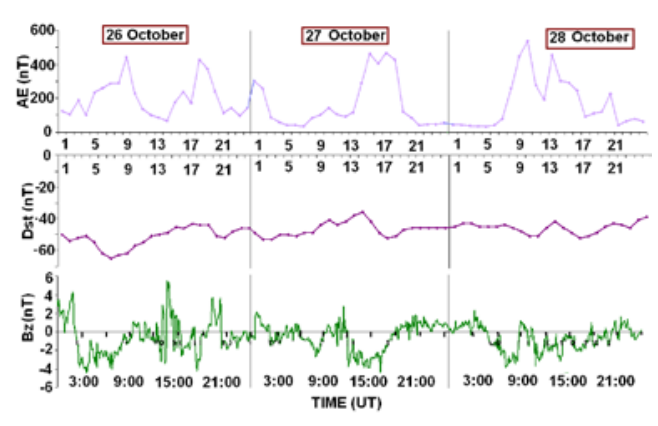

Fig. 3. Storm event of 27 Oct. 2005 with $\mathrm{AE}(\mathrm{nT})$, Dst (nT) and $\mathrm{Bz}(\mathrm{nT})$.

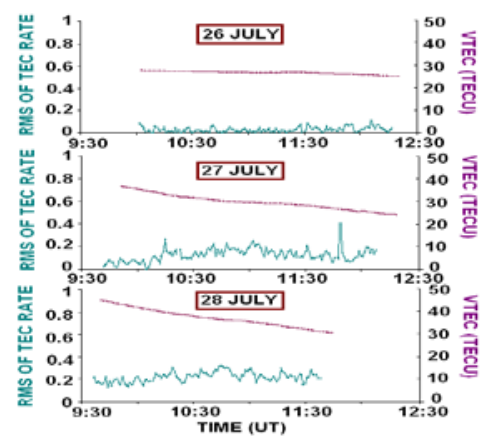

Fig. 2. Magnetic disturbance period of 27 July 2005.

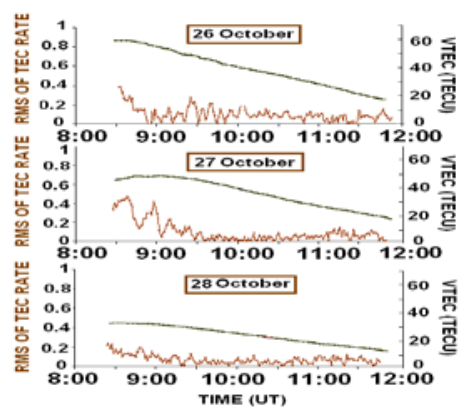

Fig. 4. Magnetic disturbance period of 27 Oct. 2005.

Similarly we can see from Fig. 3 that during the next event of 27 October 2005, AE shows its value of $468 \mathrm{nT}$ but gives the maximum value of $540 \mathrm{nT}$ on the next day i.e. on 28 October. On the storm day of 27 October, the sudden storm commencement occurred at 1156 UT and Dst reached its maximum value of $-51 \mathrm{nT}$ at around 1700UT. During the same time the IMF Bz turned southward and showed the negative component of $4.27 \mathrm{nT}$ at $1700 \mathrm{UT}$. In the same manner during geomagnetically disturbed days of 27 October, RMS of TEC rate appears quite irregular and reaches as high as 0.5 on 27 October with 
51.12 TECU as shown in Fig. 4. Such a rapid change in TEC may be related to ionospheric perturbations. During the storm the intensity of the fluctuations increases dramatically relative to quiet conditions. The occurrence of TEC fluctuations depends on the geographic and geomagnetic latitude of the site. In the Bhopal region the difference between geomagnetic and geographic coordinates of the site may be bigger than 10 degrees. At lower latitudes, fluctuations of GPS signals are attributed to small and middle scale irregularities. The intensity of phase fluctuations depends on geomagnetic activity also. The ionospheric gradients increased essentially during the storm. The irregular gradients sometimes exceeded the regular ones. During the storm, this can be the cause of major errors while determining phase ambiguities of GPS observations in the Bhopal region.

\subsection{Moderate storms}

Here we combine the TEC variations of two moderate storm events in constructing a picture of the prompt effects associated with magnetospheric disturbances at low latitude region. Fig. 5 shows the period of moderate storm of $17^{\text {th }}$ July, the maximum value of AE goes to $1064 \mathrm{nT}$ at 2400UT on the storm day when sudden storm commencement (SSC) was at $0134 \mathrm{UT}$. The main phase of the storm started about 0700UT and reached the value of $-46 \mathrm{nT}$ on that storm day. At about 1100UT, the recovery phase started but at 2200UT again the phase of the storm goes to the southward direction and reached to its second maximum of -76nT at 0700UT on 18 July. During the storm day, the IMF Bz also got its maximum value of $-11.28 \mathrm{nT}$ at 2300UT. Although the southward turning of the interplanetary magnetic field (IMF) Bz ensures the transportation of solar wind energy into the Earth's magnetosphere, which is the primary cause for the formation of geomagnetic storms [17].

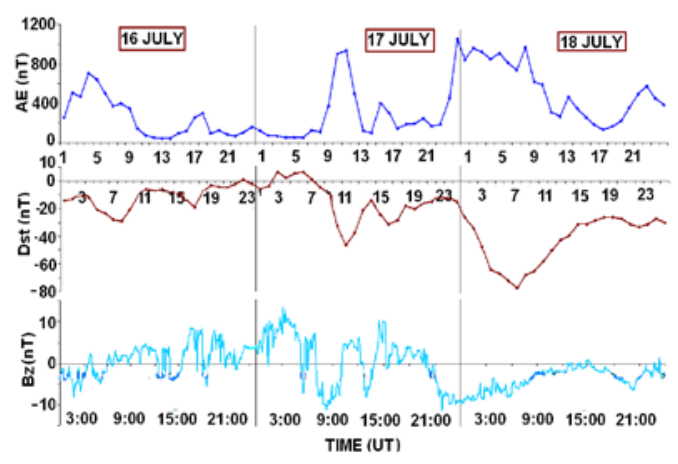

Fig. 5. Storm event of 17 July 2005 with $\mathrm{AE}(\mathrm{nT})$, Dst (nT) and Bz (nT)'

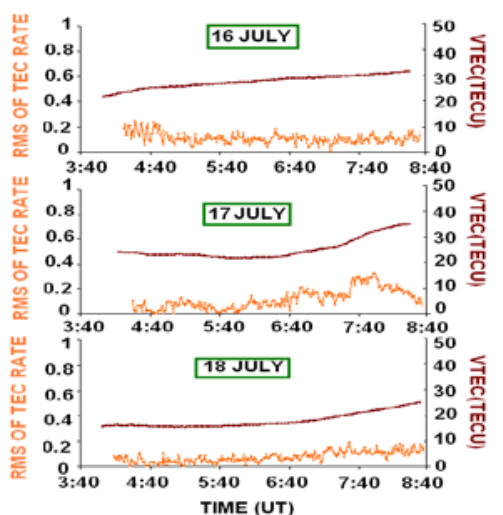

Fig. 6. Magnetic disturbance period of 17 July 2005. 
Again Fig. 6 depicts the value of RMS value of TEC rate and equivalent vertical TEC for the same period of time. During the period of moderate storm on $17^{\text {th }}$ July the TEC shows irregular behavior and RMS of TEC rate reaches upto 0.32 whereas the variation of equivalent vertical TEC 36.37 TECU was observed. The effect of the magnetic storm seemed to create enhanced effects at lower latitude as evidence by the TEC behavior.

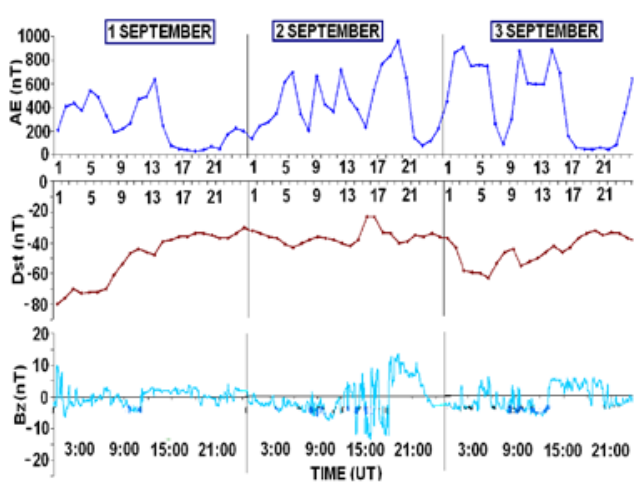

Fig. 7. Storm event of 2 Sep. 2005 with $\mathrm{AE}(\mathrm{nT})$, Dst (nT) and Bz (nT).

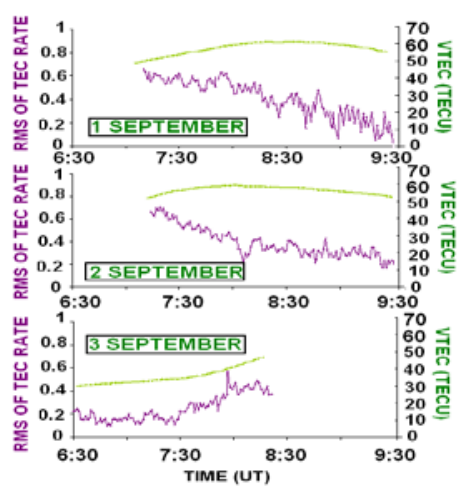

Fig.8 Magnetic disturbance period of 2 Sep. 2005

Similarly during the next moderate storm day of $2^{\text {nd }}$ September in Fig. 7, AE shows the maximum value of $947 \mathrm{nT}$ but later also AE shows many peaks during the next of storm day i.e. on $3^{\text {rd }}$ September. Sudden storm commencement was observed at 1419UT and Dst reached its maximum value of $-63 n T$ on the next day i.e. on $3^{\text {rd }}$ September. Here also during this storm day, it is evident that as time advances, IMF Bz turned southward at around 0100 UT. Except for several northward excursions, it remained negative and reached its maximum of $-13.81 \mathrm{nT}$.

During the period of moderate storm, the TEC shows irregular behavior and RMS of TEC rate reaches upto 0.7 on $2^{\text {nd }}$ September 2005 whereas the variation of equivalent vertical TEC 57.15 TECU was observed in Fig 8.

Since the RMS of TEC rate gives an idea about the intensity and occurrence of ionospheric irregularities. It is evident from the figures that during the storm day the RMS value of ROT (TEC rate) reached its maximum value indicating the presence of strong irregularities. The study shows that the strong fluctuations in TEC were caused by the presence of large-scale ionospheric structures of enhanced electron density. At the equatorial region, due to the occurrence of intense small-scale irregularities of the ionospheric F2-layer, fast variations in TEC developed and caused the degradation of positioning accuracy and quality of GPS performance. It has been found that growth of the level of geomagnetic activity is accompanied by growth of the total intensity of TEC 
variations [18]. These variations are observed due to fluctuations in TEC in the ionosphere.

\subsection{Strong storms}

In this category we have taken those storms having Dst>-90nT. During the study total of 7 strong storms occur. Out of them two storms shown here are $20^{\text {th }}$ May 2005 and $10^{\text {th }}$ July 2005. As shown in Fig. 9, AE show the value of $885 \mathrm{nT}$ at 0700UT but it reached to its maximum value of 1050 on the next day of the storm (i.e. $21^{\text {st }}$ May 2005). During the storm day of $20^{\text {th }}$ May, sudden storm commencement was at 0401UT and at about 0530UT the main phase of the storm started and reached its maximum excursion of $103 \mathrm{nT}$ at 0900UT. On the same day, IMF Bz turned southward at 0200UT to reach its maximum negative component of $-11.8 \mathrm{nT}$ and then turned northward at $0900 \mathrm{UT}$ and remained at the same direction over the several hours about 12 hours then again regain its southward direction and continue upto the $24^{\text {th }}$ hour of next day i.e. (21 ${ }^{\text {st }}$ May 2005).

As seen from the Fig. 10 the effect of the magnetic storm seemed to create enhanced effects at lower latitudes as evidence by the TEC behavior. During the period of strong storm the TEC shows irregular behavior and RMS of ROT reaches upto 0.6 with equivalent vertical TEC of 70 TECU on $20^{\text {th }}$ May.

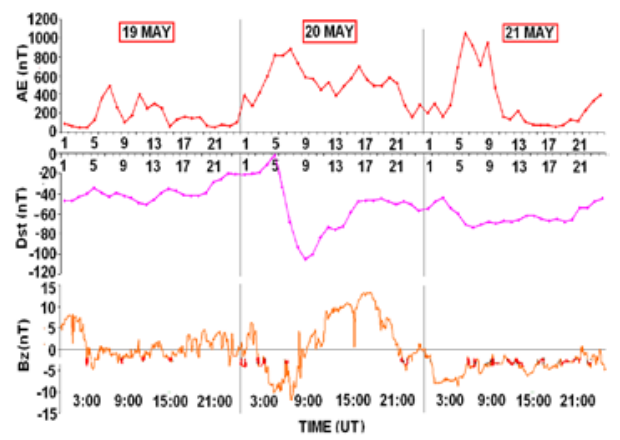

Fig. 9. Storm event of 20 May 2005 with $\mathrm{AE}(\mathrm{nT})$, Dst (nT) and $\mathrm{Bz}(\mathrm{nT})$.

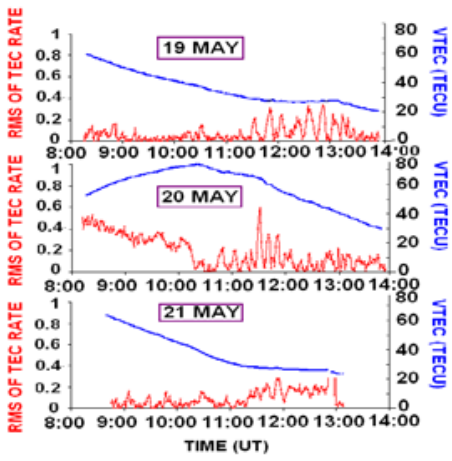

Fig. 10. Magnetic disturbance period of 20 May 2005.

During the next event of $10^{\text {th }}$ July, all the three indices show their maximum excursion on the storm day itself i.e. ( $10^{\text {th }}$ July). Fig. 11 shows that AE had its value of $1592 n T$. On the storm day sudden storm commencement was at 0337UT and main phase of the storm started at about 1200UT and reached to its maximum value of $-94 \mathrm{nT}$ at 2100UT. During this storm day, IMF Bz started fluctuating and turned to northward direction at 0300UT then again turned to southward for few hours before the turning of northward direction. Then finally turned to southward with maximum negative value of -21.8nT throughout the day and last upto the next day (i.e. $11^{\text {th }}$ July 2005). The sudden simultaneous turn in IMF 
Bz possibly suggests that there is a prompt penetration of eastward electric fields into low latitudes that augmented the normal F-region dynamo induced PRE, thereby lifting the Flayer to higher altitudes and creating conditions favorable for the development of irregularities.

During the period of strong storm on $10^{\text {th }}$ July, the TEC shows irregular behavior and RMS of ROT reaches upto 0.56 with equivalent vertical TEC of 53.66 TECU as shown in Fig. 12. It is observed from the figure that the fluctuation is high for strong storm, so it is clear that depending on the intensity of storms the fluctuation in ROT increases or decreases. Also whenever there is change in TEC this give rise to fluctuations in ROT, so it can be interpreted that there is perturbations in the ionosphere during geomagnetically disturbed days.

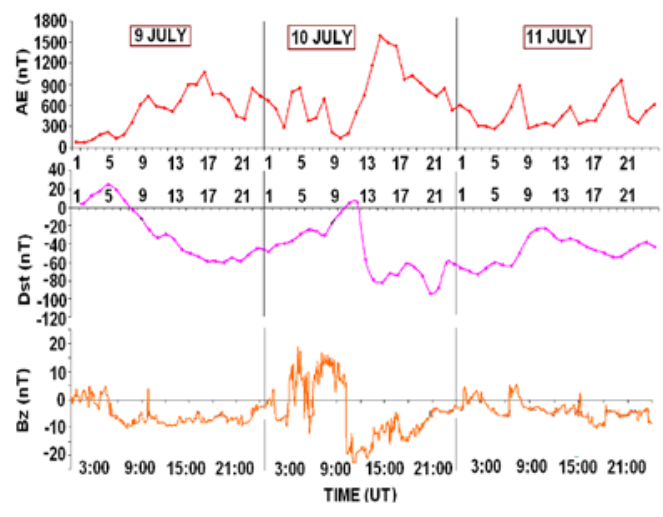

Fig. 11. Storm event of 10 July 2005 with $\mathrm{AE}(\mathrm{nT})$, Dst (nT) and Bz (nT).

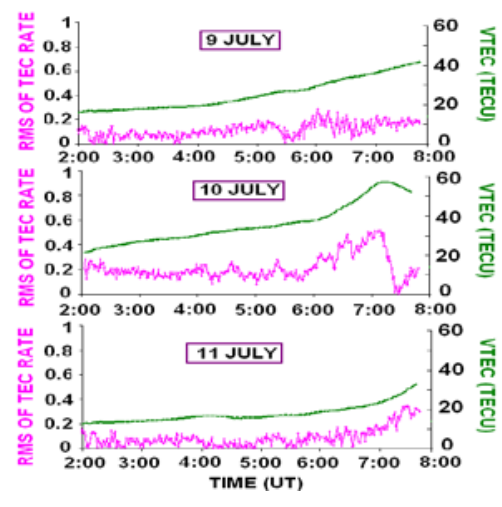

Fig. 12. Magnetic disturbance period of 10 July 2005.

The GPS data provide adequate information on phase fluctuations associated with middle and large-scale ionospheric irregularities. It is well established that the variation of GPS derived total electron content (TEC) due to geomagnetic storm effect, local low latitude electrodynamics response to penetration of high latitude convection electric field and effect of modified fountain effect on GPS-TEC in low latitude zone [19]. In ref. [2021] it has been mentioned the outstanding features produced during the storms are significant positive storm effects delayed positive effects during the night-time hours in the trough of the equatorial anomaly ("dusk" effect). To investigate the effect of perturbations on the ionosphere several scientists have focused their work showing the relation between TEC variation and ROT variation [22-23] concerning ionospheric storms.

\section{Conclusion}

It has been shown that TEC is a quiet useful parameter to design perturbations in the Magnetosphere/ionosphere/thermosphere systems. This study was undertaken using GPS 
data during the period of geomagnetic disturbances. When a perturbation appears in the ionosphere the calculated TEC will fluctuate in addition to the quick variation in the ROT. On the day of the storm, the rapid variation in ROT became more intense and occurs continuously. The ionospheric disturbances during magnetic storms are generally explained in terms of the thermospheric changes in both neutral air winds and composition, which result in changes of the rates of production and loss of ionization. In particular, geomagnetic activity of a given magnitude, as measured by standard geomagnetic indices, is seen to elicit different responses from the ionosphere in the same region, depending on the local time, season, and solar activity. To quantify the strength of ionospheric perturbations, we propose to derive temporal and spatial gradients from the generated TEC maps. In addition to solar and geomagnetic activity indices TEC map derived ionospheric perturbation indices would be helpful especially for system operators to estimate the perturbation degree of the ionosphere.

\section{References}

1. W. S. Schreiner, S. V. Sokolovsky, Rocken, and D. C. Hunt, Radio Sci. 34, 949 (1999). http://dx.doi.org/10.1029/1999RS900034

2. N. Jakowski, A. Wehrenpfennig, S. Heise, Ch. Reigber, H. Lühr, L. Grunwald, and T. K. Meehan, Geophys. Res. Lett. 29, (2002).

3. N. Jakowski, TEC Monitoring by Using Satellite Positioning Systems, Modern Ionospheric Science, eds. H.Kohl, R. Rüster, K. Schlegel, EGS, (Katlenburg-Lindau, ProduServ GmbH Verlagsservice, Berlin, 1995) pp. 371-390.

4. D. Bilitza, International Reference Ionosphere 1990, Natl. Space Sci. Data Cent. World Data Center for Rockets and Satellites, Greenbelt, Md. (1990).

http:// www.ngdc.noaa.gov/wdc/webbook/wdca/wdca_rockets

5. G. Crowley, J. Schoendorf, R. G. Roble, and F. A. Marcos, J. Geophys. Res. 101, 211 (1996). http://dx.doi.org/10.1029/95JA02584

6. R. Daniell, E. Jr., L. D. Brown, D. N. Anderson, M. W. Fox, P. H. Doherty, D. T. Decker, J. J. Sojka, and R. W. Schunk, Radio Sci. 30 (5), 1499 (1995). http://dx.doi.org/10.1029/95RS01826

7. P. Bhawre, A. A. Mansoori, P. K. Purohit, and A. K. Gwal, Preliminary Results of GPS Derived Total Electron Content Variations over Indian Antarctica Station, Maitri as part of International Polar Year, Current Research in Space Science, ISSN 2154-3097 (2011).

8. E. O. Somoye and A. O. Akala, Res. J. Phys. 4 (2), 50 (2010). http://dx.doi.org/10.3923/rjp.2010.50.55

9. A. O. Akala , E. O. Somoye, and A. B. Adeloye, Adv. Space Res. 45 (10), 1211 (2010). http://dx.doi.org/10.1016/j.asr.2010.01.004

10. S. Boutiouta and A. H. B. Boutiouta, Inform. Techn. J. 5 (5), 908 (2006). http://dx.doi.org/10.3923/itj.2006.908.915

11. C. Coker, R. Hunsucker, and G. Lott, Geophys. Res. Lett. 22,(23), 3259 (1995). http://dx.doi.org/10.1029/95GL03091

12. J. Aarons, B. Lin, M. Mendillo, K. Liou, and M. Codrescu, J. Geophys. Res. 105, A3, 5201 (2000).

13. X. Pi, A. J. Mannucci, U. J. , and C. M. Ho, Geophys. Res. Lett. 24, 2283 (1997). http://dx.doi.org/10.1029/97GL02273

14. R. Warnant and E. Pottiaux, Earth Planets Space 52, 1055 (2000).

15. S. Basu, K. M. Groves, J. M. Quinn, and P. Doherty, J. Atmos. Solar-Terrestrial Phys. 61, 1219 (1999). http://dx.doi.org/10.1016/S1364-6826(99)00052-8 
16. A. Bhattacharyya, T. L. Beach, S. Basu, and P. M. Kintner, Radio Science 35, 209 (2000). http://dx.doi.org/10.1029/1999RS002213

17. W. D. Gonzales, J. A. Joselyn, Y. Kamide, H. W. Kroehl, G. Rostoker, B. T. Tsurutani, and V. M. Vasyliunas, J. Geophys. Res. 99, 5771 (1994). http://dx.doi.org/10.1029/93JA02867

18. E. L. Afraimovich, V. V. Demyanov, and T. N. Kondakova, GPS Solutions 7 (2), 109 (2003). http://dx.doi.org/10.1007/s10291-003-0053-7

19. S. Kumar and A. K. Singh, Adv. Space Res. 47 (4), 710 (2011). http://dx.doi.org/10.1016/j.asr.2010.10.015

20. G. A. Mansilla, Adv. Space Res. 48 (3), 478 (2011). http://dx.doi.org/10.1016/j.asr.2011.03.034

21. H. Chaurasia and A. K. Gwal, Study of total electron content of ionosphere over low and high latitude region, Bhartiya Vaigyanik evam Audyogik Anusandhan Patrika (BVAAP) 18 (2), 162 (2010).

22. T. J. Fuller-Rowell, M. V. Codrescu, R. G. Roble, and A. D. Richmond, How does the thermosphere and ionosphere react to a geomagnetic storm?, in Magnetic Storms, Geophys. Monogr. Ser. 98, 203, AGU, Washington, D. C. (1997).

23. M. Aggarwal, TEC variability near northern EIA crest and comparison with IRI model, Adv. Space Res. 48 (7) 1221 (2011). http://dx.doi.org/10.1016/j.asr.2011.05.037 